\title{
Antrodia cinnamomea fruiting bodies extract suppresses the invasive potential of human liver cancer cell line PLC/PRF/5 through inhibition of nuclear factor $\kappa \mathrm{B}$ pathway is
}

\author{
Ya-Ling Hsu ${ }^{\text {a }}$, Po-Lin Kuo ${ }^{b}$, Chien-Yu Cho ${ }^{c}$, Wen-Chiu Ni ${ }^{b}$, Tz-Fei Tzeng ${ }^{c}$, \\ Lean-Teik $\mathrm{Ng}^{\mathrm{d}}$, Yueh-Hsiung Kuo ${ }^{\mathrm{e}}$, Chun-Ching Lin ${ }^{\mathrm{f}, *}$ \\ ${ }^{a}$ Department of Pharmacy, Chia-Nan University of Pharmacy and Science, Tainan, Taiwan \\ ${ }^{\mathrm{b}}$ Cell Biology Laboratory, Department of Biotechnology, Chia-Nan University of Pharmacy and Science, Tainan, Taiwan \\ ${ }^{\mathrm{c}}$ Graduate Institute of Natural Products, Kaohsiung Medical University, Kaohsiung, Taiwan \\ d Department of Biotechnology, Tajen University, Pingtung, Taiwan \\ ${ }^{\mathrm{e}}$ Department of Chemistry, National Taiwan University, Taipei, Taiwan \\ ${ }^{\mathrm{f}}$ Faculty of Pharmacy, College of Pharmacy, Kaohsiung Medical University, Kaohsiung, Taiwan
}

Received 1 August 2006; accepted 6 January 2007

\begin{abstract}
In this study, we first report the anti-invasive effect of ethylacetate extract from Antrodia cinnamomea (EAC) fruiting bodies in the human liver cancer cell line PLC/PRF/5. Treatment with EAC decreased the cancer invasion of PLC/PRF/5 cells in a dose-dependent manner. This effect was strongly associated with a concomitant decrease in either the level or activity of VEGF, MMP-2, MMP-9 and MT1-MMP, and an increase in the expression of TIMP-1 and TIMP-2. EAC inhibited constitutively activated and inducible NF- $\kappa$ B in both its DNA-binding activity and transcriptional activity. Furthermore, EAC also inhibited the TNF- $\alpha$-activated NF- $\kappa B-d e p e n d e n t$ reporter gene expression of MMP-9 and VEGF, and the invasion of cancer cells. EAC also exhibited an inhibitory effect on angiogenesis in a Matrigel Plug Angiogenesis Assay. Further investigation revealed that EAC's inhibition of cancer cell growth and invasion was also evident in a nude mice model. Our results indicate that EAC inhibits the activation of $\mathrm{NF}-\kappa \mathrm{B}$, and may provide a molecular basis for drug development using EAC as an anti-invasive agent in the prevention and treatment of cancer.
\end{abstract}

(C) 2007 Elsevier Ltd. All rights reserved.

Keywords: Antrodia cinnamomea; Invasion; Liver cancer; MMPs; NF-кB

\section{Introduction}

Tumor invasiveness and metastasis are characteristics of highly malignant cancers with poor clinical outcome (Qin and Tang, 2004; Christofori, 2006). Tumor invasion is a perplexing cascade process involving a finely tuned interac-

\footnotetext{
The generic name of Antrodia camphorata is currently corrected by Chang and Chou (Chang and Chou, 2004).

* Corresponding author. Tel.: +886 7 3121101x2122; fax: +886 7 3135215.

E-mail address: aalin@kmu.edu.tw (C.-C. Lin).
}

tion between cancer cells and various regulated factors (Christofori, 2006). As cancer cells become invasive and metastatic, they alter the affinity of extracellular matrix (ECM), such as basement membrane. Excess breakdown of ECM is one of the hallmarks of tumor invasion and metastasis (Christofori, 2006; Huang et al., 2002; Hofmann et al., 2005). MMPs are members of zinc-dependent endopeptidases family which is associated with the degradation of ECM during tissue remodeling. Among all MMPs, MMP-2 and MMP-9 (gelatinase A and B, respectively) have been implicated as important factors in facilitating invasion and metastases in liver cancer (Hofmann et al., 
2005; Hou et al., 2001). MMPs have a unique capability to degrade type IV collagen, which is a major component of the basement membrane. Overexpression of MMP-2/-9 has been associated with increased metastatic potential in many tumor cells (Hofmann et al., 2005). In contrast to MMP-2 and MMP-9, which are secreted and as soluble enzymes, membrane-type MMPs (MT-MMPs) contain either an additional transmembrane domain (MT-1-, MT-2-, MT-3-, and MT-5-MMP) or a glycosylphosphatidyl-inositol anchor (MT-4-, and MT-6-MMP), resulting in cell surface localization. MT-1-MMP degrades a number of ECM proteins, stimulates angiogenesis, promotes tumor invasion and growth, and is also involved in activation of proMMP-2 (Hofmann et al., 2005; Zucker et al., 2000; Ko et al., 2005). Indeed, the activity of MMPs is regulated by a series of naturally occurring tissue inhibitors of matrix metalloproteinases (TIMPs). At least four different structurally related members (TIMP-1 to TIMP-4) have been identified (Ikenaka et al., 2003). The TIMPs bind either to proMMPs or active MMPs, thereby inhibiting the autocatalytic activation of latent MMP enzymes and the proteolytic capacity of active proteinases (Chirco et al., 2006). Furthermore, vascular endothelial growth factor (VEGF), the most well-characterized angiogenic factor, is known to play an important role in tumor-associated microvascular invasion (Huang et al., 2005).

The transcription factor nuclear factor $\kappa \mathrm{B}(\mathrm{NF}-\kappa \mathrm{B})$ regulates the expression of a wide variety of genes involved in cellular events such as inflammation, immune response, proliferation, apoptosis, and cancer invasion (Dixit and Mak, 2002; Herr and Debatin, 2001; Woodworth et al., 2005). NF- $\mathrm{kB}$ has been reported to modulate the expression of several genes whose products are associated with tumor development (Aggarwal, 2004; Karin et al., 2002). These include antiapoptotic genes (i.e., c-FLIP, Bfl-1, $\mathrm{Bcl}-2, \mathrm{Bcl}-X_{\mathrm{L}}$, and XIAP), cancer invasiveness genes (i.e., matrix metalloproteinases (MMP)-9, urokinase, VEGF and COX-2) and cell cycle-related genes (i.e., c-Myc and cyclin D1) (Denoyelle et al., 2001; Shishodia et al., 2005; Srivastava and Singh, 2004). NF- $\kappa B$ can also decrease the induction of apoptosis mediated by genotoxic chemotherapeutic agents and ionizing radiation. Cancer cells in which $\mathrm{NF}-\kappa \mathrm{B}$ is constitutively active are highly resistant to anticancer agents or ionizing radiation, and inhibition of NF$\kappa \mathrm{B}$ activity in these cells greatly decreases their invasiveness (Dixit and Mak, 2002; Herr and Debatin, 2001; Munshi et al., 2004).

In our earlier report, we showed that EAC inhibits liver cancer cells by inducing apoptosis in Hep G2, PLC/PRF/5, and Hep 3B (Kuo et al., 2006; Hsu et al., 2005b). EAC induces apoptosis of Hep 3B cells through calcium and calpain-dependent pathways, whereas it decreases NF- $\mathrm{B}$ cell survival signaling in Hep G2 and PLC/PRF/5 cells (Kuo et al., 2006; Hsu et al., 2005b). Therefore, in this study we investigated whether EAC may lead to the down-regulation of invasion-related factor through NF- $\mathrm{KB}$ inhibition, thereby inhibiting invasion of human liver cancer cells.
Our results suggest that EAC causes a decrease in the expression of MMP-2, MMP-9, MT-1-MMP, and VEGF, resulting in the inhibition of human liver cancer cell invasion.

\section{Materials and methods}

\subsection{Cell invasion assay}

BD BioCoat tumor invasion system (BD Biosciences) was used to assess invasion by PLC/PRF/5 cells. Briefly, PLC/PRF/5 cells $\left(5 \times 10^{4}\right)$ with serum-free medium were seeded into the upper chamber of the system. Bottom wells in the system were filled with $20 \%$ FBS or TNF- $\alpha$ $(100 \mathrm{ng} / \mathrm{ml})$. After $24 \mathrm{~h}$ of incubation, the cells in the upper chamber were removed, and the cells which had invaded through the Matrigel matrix membrane were stained with $4 \mu \mathrm{g} / \mathrm{mL}$ Calcein AM in Hanks buffered saline at $37{ }^{\circ} \mathrm{C}$ for $1 \mathrm{~h}$. Then, fluorescence of the invaded cells was read in a fluorescence plate reader at excitation/emission wavelengths of 485/ $530 \mathrm{~nm}$

\subsection{Electrophoretic mobility shift assay (EMSA)}

The nuclear extract was prepared using Nuclear Extract kit (Active Motif, Carlsbad, CA) according to the manufacturer's specifications. EMSA was performed by using lightshift chemiluminescent EMSA kit (Pierce, Rockford, IL, USA) following the manufacturer's protocol. Five micrograms nuclear protein, 50 fmole $3^{\prime}$-biotin labeled DNA probes, and double-stranded NF- $\mathrm{BB}$ oligonucleotides (5'-AGTTGAGGGGACTTTCCCAGGC-3' and 3'-TCAACTCCCCTGAAAGGGTCCG$\left.5^{\prime}\right)$ were mixed in the binding reagent containing $1 \times$ binding buffer (100 mM Tris, $500 \mathrm{mM} \mathrm{KCl,} 10 \mathrm{mM}$ dithiothreitol), (pH 7.5), 2.5\% glycerol, $5 \mathrm{mM} \mathrm{MgCl}_{2}, 50 \mathrm{ng} / \mathrm{mL}$ poly $(\mathrm{dI}-\mathrm{dC})$, and $0.05 \%$ NP- 40 . After incubation for $30 \mathrm{~min}$, the reaction mixture was subjected to gel electrophoresis on $8 \%$ native polyacrylamide gel and transferred to a nylon membrane. The biotin end-labeled DNA was detected using streptavidinhorseradish peroxidase conjugate and chemiluminescence blotting detection system.

\section{3. $N F-\kappa B$ reporter assay}

$\mathrm{NF}-\kappa \mathrm{B}-$ dependent reporter plasmid (NF- $\kappa \mathrm{B}-\mathrm{SEAP}$ ), designed to monitor the transcription factor binding activity of NF- $\mathrm{KB}$ through the use of a SEAP assay, was purchased from BD Biosciences (San Jose, CA). $\mathrm{PLC} / \mathrm{PRF} / 5$ cells were transiently co-transfected with NF-kB-SEAP and M1- $\beta$-Gal plasmid (Roche Diagnostics, GmbH) using Lipofectamine 2000 reagent. SEAP and galactosidase expression was determined with the SEAP assay system and $\beta$-galactosidase assay system respectively (Roche, Germany), according to the reference protocol. SEAP expression was normalized to $\beta$-galactosidase expression to control for transfection efficiency. Relative SEAP activity was determined to reflect the transcriptional activity of $\mathrm{NF}-\kappa \mathrm{B}$, and expressed as fold increases relative to the activity of untreated controls.

\subsection{MMP-2, MMP-9, and VEGF assay}

The culture medium of the PLC/PRF-5 cells grown in six-well plates was collected. After collection, the medium was centrifuged at $800 \mathrm{~g}$ for $3 \mathrm{~min}$ at $4{ }^{\circ} \mathrm{C}$ to remove cell debris. The supernatant was immediately assayed using commercially available MMP-2, MMP-9, and VEGF ELISA kits (R\&D Systems, Inc., Minneapolis, MN).

\subsection{Gelatin zymography}

PLC/PRF/5 cells were treated with $30 \mu \mathrm{g} / \mathrm{ml}$ of EAC in serum-free DMEM medium for $24 \mathrm{~h}$. The conditioned media were collected and analyzed for MMPs using gelatin zymography. MMPs were separated by 
$7.5 \%$ SDS-polyacrylamide gels that had been co-polymerized with $0.1 \%$ gelatin under non-reducing conditions. The loading volume of each sample was normalized according to the cell number. After electrophoresis, gels were washed twice for $60 \mathrm{~min}$ in wash buffer $(50 \mathrm{mM}$ Tris- $\mathrm{HCl}$, $\mathrm{pH} 7.5$, containing $1 \%$ Triton $\mathrm{X}-100$ ) to remove SDS, then incubated in reaction buffer $(50 \mathrm{mM}$ Tris- $\mathrm{HCl}, \mathrm{pH} 7.5$, containing $1 \%$ Triton $\mathrm{X}-100$, $10 \mathrm{mM} \mathrm{CaCl}_{2}, 150 \mathrm{mM} \mathrm{NaCl}$, and $0.01 \% \mathrm{NaN}_{3}$ ) for $24 \mathrm{~h}$ at $37^{\circ} \mathrm{C}$. Gels were stained with $0.2 \%$ Coomassie blue in $30 \%$ methanol $/ 10 \%$ acetic acid for $60 \mathrm{~min}$ and destained in $30 \%$ methanol $/ 10 \%$ acetic acid. The presence of MMPs was indicated as a clear unstained band.

\subsection{Western blot analysis}

Cells $\left(8 \times 10^{6} /\right.$ dish $)$ were seeded in a $10 \mathrm{~cm}$ dish. After $24 \mathrm{~h}$ of incubation, the cells were treated with various concentrations of EAC for the indicated times. Total cell extracts were prepared in lysis buffer $(50 \mathrm{mM}$ Tris- $\mathrm{HCl}, 150 \mathrm{mM} \mathrm{NaCl}, 1 \mathrm{mM}$ EGTA, $1 \mathrm{mM}$ EDTA, $20 \mathrm{mM} \mathrm{NaF}$, $100 \mathrm{mM} \mathrm{Na}{ }_{3} \mathrm{VO}_{4}, 0.5 \%$ NP-40, $1 \%$ Triton X-100, $1 \mathrm{mM}$ PMSF, $5 \mu \mathrm{g} / \mathrm{mL}$ Aprotinin, $5 \mu \mathrm{g} / \mathrm{mL}$ Leupetin). Equivalent amounts of protein were resolved by SDS-PAGE and transferred to PVDF membranes. After the membrane was blocked in Tris-buffer saline containing $0.05 \%$ Tween 20 (TBST) and 5\% non-fat powdered milk, the membranes were incubated with primary antibodies at $4{ }^{\circ} \mathrm{C}$ for $1-16 \mathrm{~h}$. After washing three times with TBST for 10 min each, the membranes were incubated with horseradish peroxidase-labeled secondary antibody for $1 \mathrm{~h}$. The membranes were washed again, and detection was performed using the enhanced chemiluminescence blotting detection system (Amersham, USA) (Hsu et al., 2005a).

\subsection{Matrigel plug angiogenesis assay}

Male nude mice [6 weeks old; BALB/cA-nu (nu/nu)] were purchased from the National Science Council Animal Center (Taipei, Taiwan) and maintained in pathogen-free conditions. Eight mice were randomly divided into two groups. PLC/PRF/5 cells were trypsinized and resuspended at $3 \times 10^{7}$ cells $/ \mathrm{ml}$ in serum-free medium. Aliquots of cells $\left(3 \times 10^{6}\right.$ cells/ $0.1 \mathrm{ml}$ ) were mixed with $0.2 \mathrm{ml}$ of phenol red-free Matrigel (BD Biosciences) and injected into both flanks of each nude mouse. For the EACtreated group, the cell suspensions were added EAC $(30 \mu \mathrm{g} / \mathrm{ml})$. The Matrigel mixed with the medium alone was used as a negative control. Matrigel plugs were removed 15 days after implantation, weighed, and used for the measurement of hemoglobin content using a Drabkin's reagent kit (contains sodium bicarbonate, potassium ferricyanide, and potassium cyanide) (Liu et al., 2005). The levels of hemoglobin were measured as an indication of blood vessel formation (Pan et al., 2005).

\subsection{In vivo tumor model}

Male nude mice [6 weeks old; BALB/cA-nu (nu/nu)] were purchased from the National Science Council Animal Center (Taipei, Taiwan) and maintained in pathogen-free conditions. PLC/PRF/5 cells were injected subcutaneously into the flanks of nude mice $\left(5 \times 10^{6}\right.$ cells in $\left.200 \mu \mathrm{l}\right)$. Tumors were allowed to develop until they reached $\sim 100 \mathrm{~mm}^{3}$, when treatment was initiated. Twenty mice were randomly divided into two groups. The mice in the EAC-treated group were p.o. with EAC in Tween 80: ethanol: water $(1: 1: 8)(300 \mathrm{mg} / \mathrm{kg}$ of body weight) in a $0.2-\mathrm{ml}$ volume. The control group was treated with an equal volume of vehicle. After transplantation, tumor size was measured using calipers, and tumor volume was estimated according to the formula: tumor volume $\left(\mathrm{mm}^{3}\right)=L \times W^{2} / 2$, where $L$ is the length and $W$ is the width (Hsu et al., 2006).

\subsection{Statistical analysis}

Data were expressed as means $\pm \mathrm{SD}$ of three independent determinations. Statistical comparisons of the results were made using analysis of variance (ANOVA). Significant differences $(P<0.05)$ between the means of the two test groups were analyzed by Dunnett's test.

\section{Results}

\subsection{Effects of EAC on invasion of PLC/PRF/5 cells}

To examine the effect of EAC on the invasion of human liver cancer cells, a Matrigel invasion chamber was used to examine the invasive potential of $\mathrm{PLC} / \mathrm{PRF} / 5$ cells. As shown in Fig. 1, treatment of EAC for $24 \mathrm{~h}$ exhibited significant inhibition of cell invasion in a dose-dependent manner.

\subsection{EAC down-regulates the expression of VEGF, MMP-2, $M M P-9$, and MT-1-MMP, and up-regulates the levels of TIMP-1 and TIMP-2 protein in PLC/PRF/5 cells}

Because MMP-2, MMP-9, TIMP-1, TIMP-2, MT1MMP, and VEGF have been indicated to be associated with cancer invasion, we therefore investigated whether these molecules were involved in EAC-mediated invasion down-regulation. As shown in Fig. 2a-c, EAC treatment decreased the levels of MMP-2, MMP-9, and VEGF in a time-dependent manner as determined by ELISA method. The TIMPs and MT-1-MMP protein expressions were investigated to further explore the modulated activation of the pro-MMPs as mediated by EAC. Western blot assay showed that EAC treatment decreased the expression of MT1-MMP and increased the levels of TIMP-1 and TIMP-2 proteins (Fig. 2d).

Next, we assessed that effect of EAC on the activity of MMP-2 and MMP-9 by zymography assay. As shown in Fig. 2e, EAC treatment decreased the activity of MMP and MMP-9 in a dose-dependent manner.

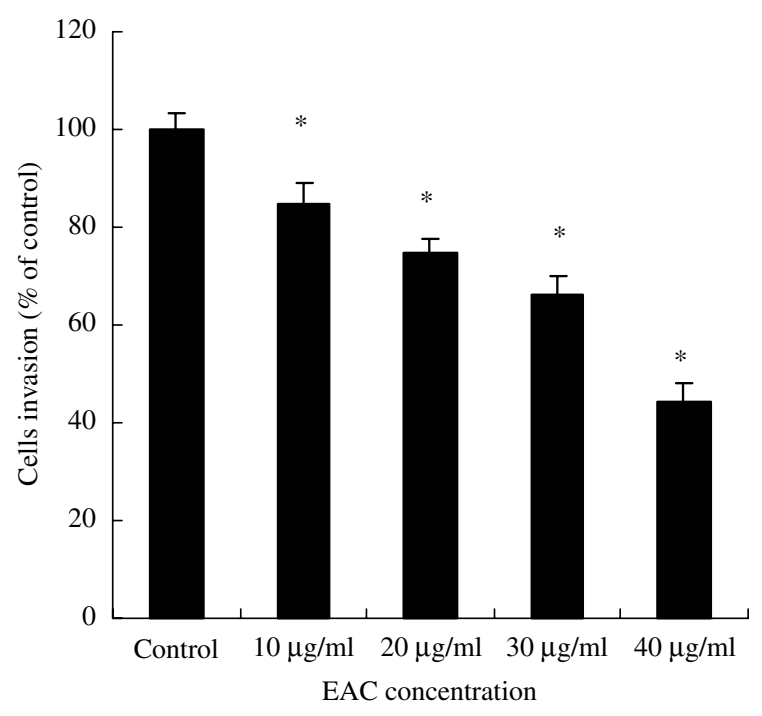

Fig. 1. EAC inhibited PLC/PRF/5 invasion. Cells were treated with various concentration of EAC for $24 \mathrm{~h}$. The invasive ability of PLC/PRF/ 5 was assessed by BD BioCoat tumor invasion system, according to the description in Section 2. Each value is the mean $\pm \mathrm{SD}$ of three independent determinations. The asterisk indicates a significant difference between two test groups, ${ }^{*} p<0.05$. 

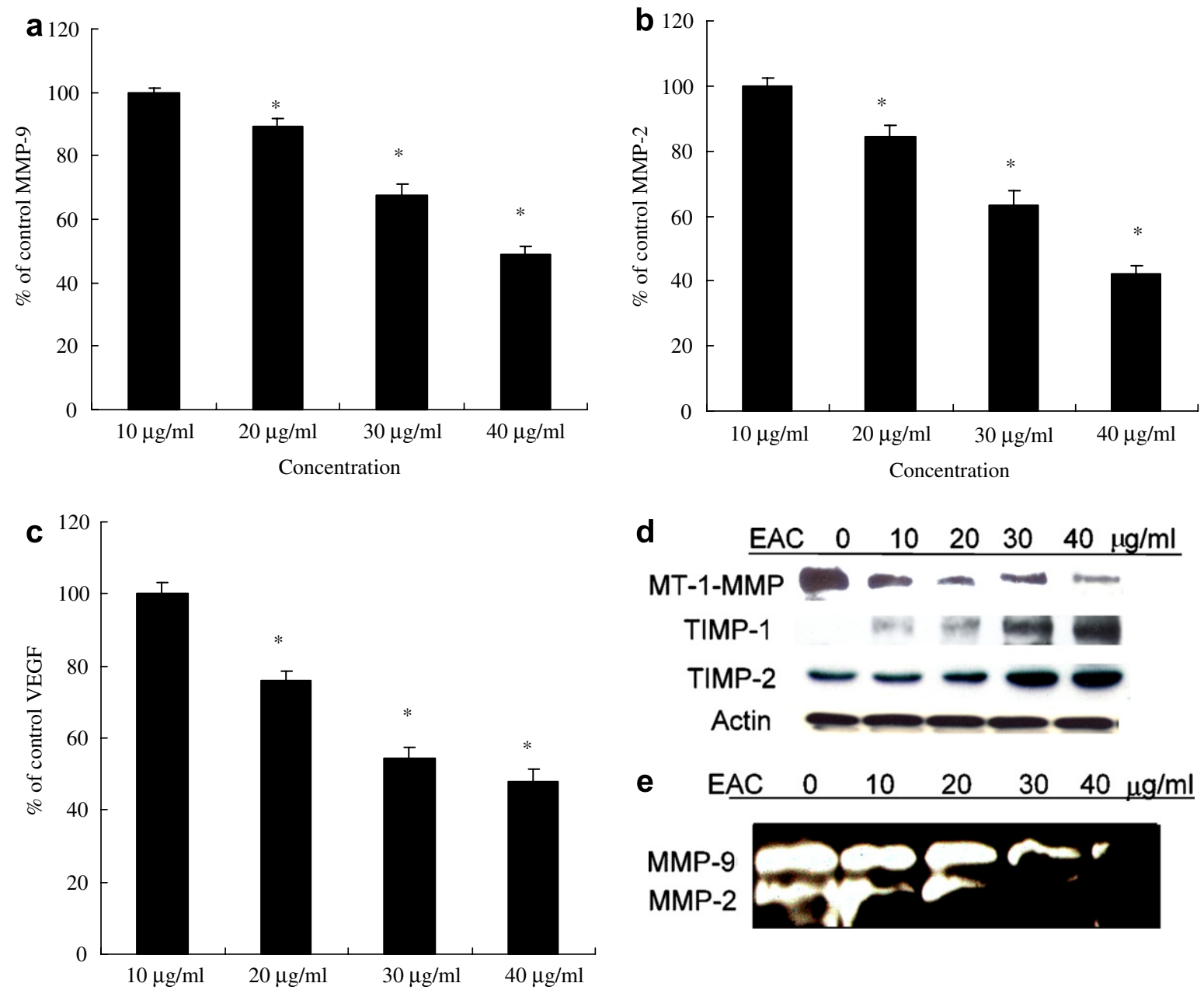

Fig. 2. The effect of EAC on the expression and/or activity of MMPs, MT-1-MMP, TIMP, and VEGF. EAC decreased the expression of MMP-9 (a), MMP-2 (b), and VEGF (c). (d) The effect of EAC on the expression of MT-1-MMP and TIMPs. (e) EAC decreased the activity of MMP-2 and MMP-9. Cells were treated with EAC for $12 \mathrm{~h}$, and the expression of MMP-9, MMP-2, VEGF was assessed by ELISA kits. The levels of MT-1-MMP and TIMPs were determined by Western blot. MMP-2 and MMP-9 activity was assessed by gelatin zymography. Each value is the means \pm SD of three independent determinations. The asterisk indicates a significant difference between two test groups, ${ }^{*} p<0.05$.

\subsection{Effects of EAC on constitutive $N F-\kappa B$ binding and transcriptional activity}

The NF- $\mathrm{KB}$ is a key player in the signaling transduction pathway of invasion in cancer. Therefore, we measured the effect of EAC on both NF-кB DNA-binding and transcriptional activity. As shown in Fig. 3a and b, NF- $\mathrm{kB}$ was constitutively activated in PLC/PRF/5 in both the DNAbinding activity (EMSA) and transcriptional activity (plasmid reporter assay). EAC treatment, however, inhibited the $\mathrm{NF}-\kappa \mathrm{B}$ activation after $6 \mathrm{~h}$ exposure.

\subsection{Effects of EAC on TNF- $\alpha$-induced $N F-\kappa B$ activation, cell invasion, and the induction of $N F-\kappa B$ 's downstream $M M P S$}

$\mathrm{NF}-\kappa \mathrm{B}$ has been reported to play an important role in tumor invasion, and the expression of MMPs and VEGF. TNF- $\alpha$ has been found to increase the activation of NF$\kappa \mathrm{B}$, and then increase the expression of NF- $\kappa \mathrm{B}$ 's down- stream molecules. We examined whether EAC decreases MMPs expression by inhibiting the activation of NF- $\mathrm{KB}$. As shown in Fig. 4a and b, EAC treatment is seen to inhibit $\mathrm{NF}-\kappa \mathrm{B}$ activation induced by TNF- $\alpha$ in PLC/PRF/5, in both the EMSA and plasmid reporter assays. Pretreatment of PLC/PRF/5 cells with EAC $(40 \mu \mathrm{g} / \mathrm{ml}, 6 \mathrm{~h}$ exposure) suppressed the activation of NF- $\kappa \mathrm{B}$ induced by TNF- $\alpha$. These results suggest that EAC not only inhibits constitutive NF- $\kappa \mathrm{B}$ activation, but also aborted TNF- $\alpha$-induced $N F-\kappa B$ activation.

We also investigated whether EAC can decrease NF- $\kappa B-$ regulated gene products, induced by TNF- $\alpha$, which are involved in the cancer invasion. Pretreatment of cells with or without EAC was examined for TNF- $\alpha$-induced cancer invasion and gene products. As shown in Fig. 4c, TNF- $\alpha$ treatment increased $\mathrm{PLC} / \mathrm{PRF} / 5$ cell invasion, and $\mathrm{EAC}$ decreased the induction of TNF- $\alpha$-induced cancer invasion. In addition, TNF- $\alpha$ treatment increased the expression or activity of MMP-9 and VEGF. In contrast, when cells were pre-incubated with EAC, the induction effects of TNF- $\alpha$ on 

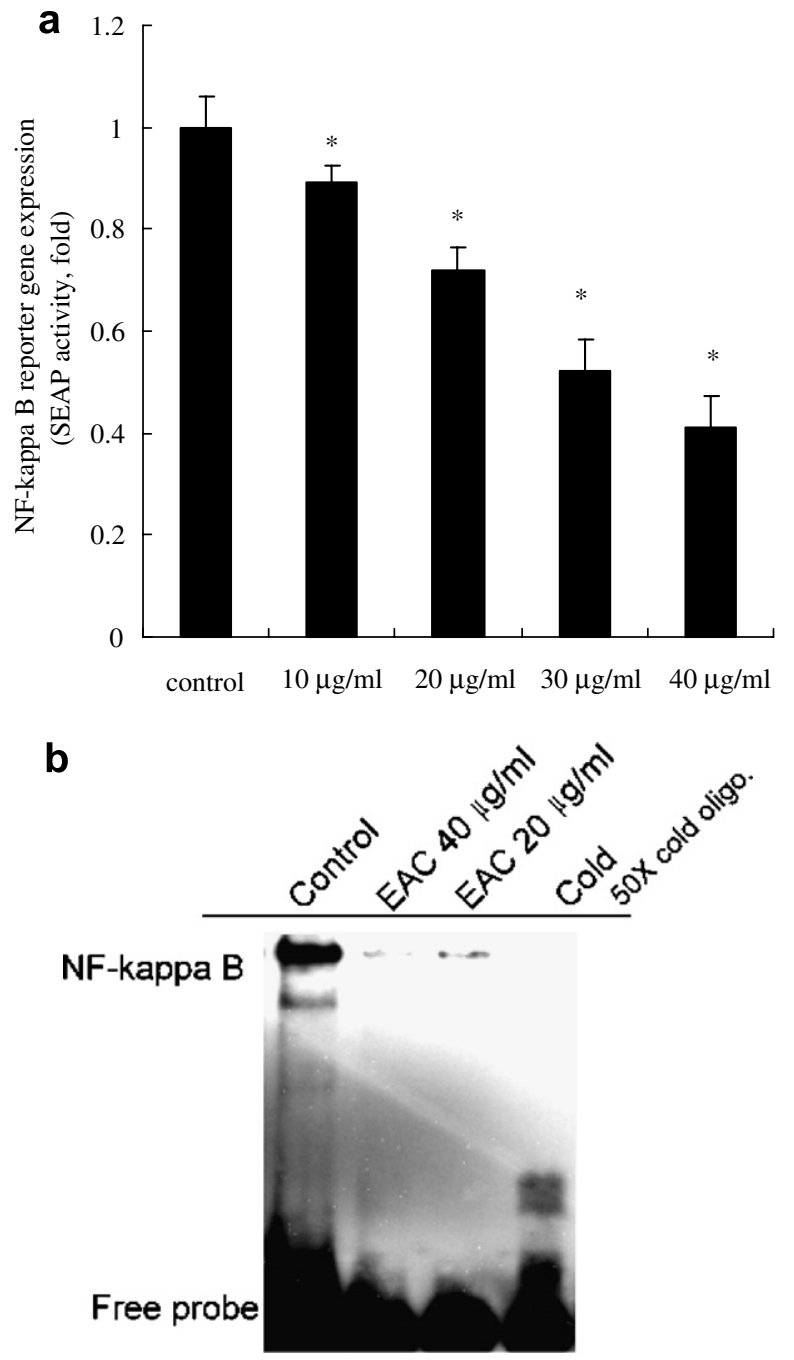

Fig. 3. Effects of EAC on constitutive NF- $\mathrm{\kappa B}$ binding and transcriptional activity. (a) EAC inhibited the transcriptional activity of NF-кB. (b) EAC decreased the DNA-binding activity of NF- $\mathrm{BB}$. For (a), cells were transiently transfected with an NF-кB-containing SEAP reporter gene plasmid alone, or with the indicated plasmids for $24 \mathrm{~h}$. Following transfection, cells were treated with EAC $(30 \mu \mathrm{g} / \mathrm{ml})$ for $6 \mathrm{~h}$, and the supernatants of the culture medium were assayed for SEAP activity, as described in Section 2. For (b), cells were treated with EAC (30 $\mu \mathrm{g} / \mathrm{ml})$ for $6 \mathrm{~h}$, and the DNA binding and transcriptional activity was assessed by EMSA. Each value is the means \pm SD of three independent determinations. The asterisk indicates a significant difference between two test groups, ${ }^{*} p<0.05$.

the activity and protein expression of MMP-9 and VEGF were inhibited (Fig. 4e-f).

\subsection{Inhibitory effect of EAC on angiogenesis in nude mice model}

Since angiogenesis has been proven to be involved in cancer invasion and metastasis, we therefore also tested whether EAC inhibits angiogenesis in an in vivo model. PLC/PRF/5 cells were mixed with Matrigel and injected into both flanks of nude mice. Relative angiogenesis was assayed by the hemoglobin content of the Matrigel plug.
Compared with the Matrigel mixed with the medium alone, $\mathrm{PLC} / \mathrm{PRF} / 5$ cells greatly induced angiogenesis, and the hemoglobin levels in the PLC/PRF/5 cell-added Matrigel plugs were 6.4-fold higher than those in the Matrigel alone. EAC treatment inhibited PLC/PRF/5 cell-induced angiogenesis, and the hemoglobin levels in the EAC-treated plug were significantly lower than those in the solvent-treated plugs (Fig. 5). These results suggest that EAC treatment decreased angiogenesis of $\mathrm{PLC} / \mathrm{PRF} / 5$ in the in vivo model.

\subsection{Inhibitory effect of EAC on tumor growth in nude mice model}

We recently demonstrated that EAC exerts its antiproliferation activity through the inhibition of NF- $\kappa \mathrm{B}$ in two human liver cancer lines, Hep G2 and PLC/PRF/5, in vitro (Kuo et al., 2006). We therefore tested whether EAC inhibits tumor growth in vivo. Tumor growth inhibition was most evident in mice treated with EAC at $300 \mathrm{mg} /$ $\mathrm{kg} /$ day, where about $50 \%$ reduction in tumor size was observed, in contrast with mice treated with the vehicle (Fig. 6). No sign of toxicity, as judged by parallel monitoring of body weight, was observed in EAC-treated mice.

\section{Discussion}

Hepatocellular carcinoma (HCC) is one of the most lethal malignancies, and is also one of the four most prevalent malignant diseases of adults in China, Taiwan, Korea, and Sub-Sahara Africa (Marrero, 2006; Motola-Kuba et al., 2006). A. cinnamomea, a traditional Chinese herb, is found locally in Taiwan. It has been widely used to treated cancer and inflammation, and reported to possess antioxidative, anti-inflammatory, hepatoprotective, vasorelaxative, and anti-hepatitis B virus effects (Hsiao et al., 2003; Lee et al., 2002; Shen et al., 2004; Song and Yen, 2002; Wang et al., 2003). Previous studies revealed that an activated steroid acid of $A$. cinnamomea fruiting bodies, zhankuic acid, exhibited a significant cytotoxic effect against P338 murine leukemia (Liu et al., 2004). The maleic and succinic acid derivatives of the mycelium of $A$. cinnamomea also showed appreciable cytotoxicity against LLC cells (Nakamura et al., 2004). Our previous study indicated that ethylacetate extract of $A$. cinnamomea fruiting bodies (EAC) inhibits the proliferation of human cancer cells lines by inducing apoptosis (Kuo et al., 2006; Hsu et al., 2005b). In this study, we further report on the cancer invasion inhibition effect of EAC in human liver cancer PLC/PRF/5 cells. Moreover, EAC treatment not only inhibited cancer invasion in $\mathrm{PLC} / \mathrm{PRF} / 5$ cells, but it also decreased tumor growth and angiogenesis in vivo. EAC treatment inhibited the expression of VEGF, MMP-2, and MMP-9, and increased the expression of TIMP-1 and TIMP-2, thereby resulting in cancer invasion inhibition. Further analysis revealed that EAC suppressed constitutive and inducible $\mathrm{NF}-\mathrm{\kappa B}$, together with a reduction in MMP-9 and VEGF 


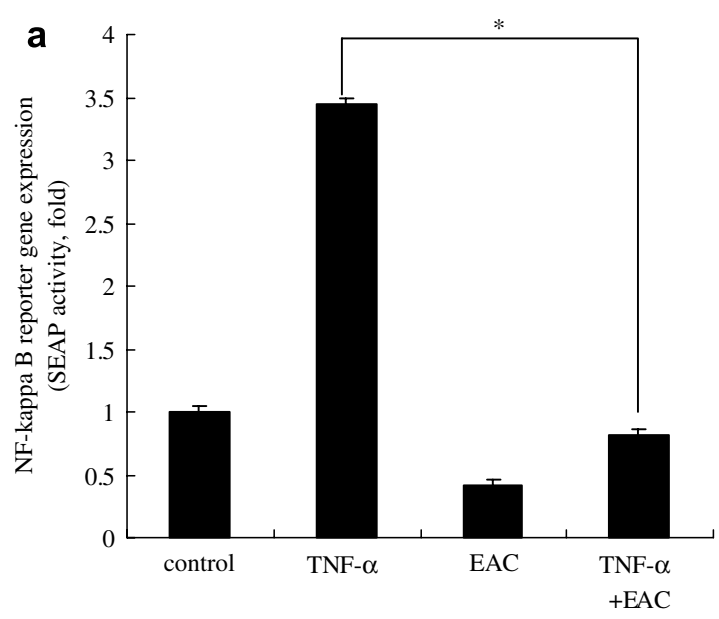

b

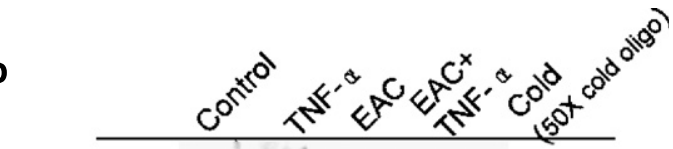

NF-kappa B
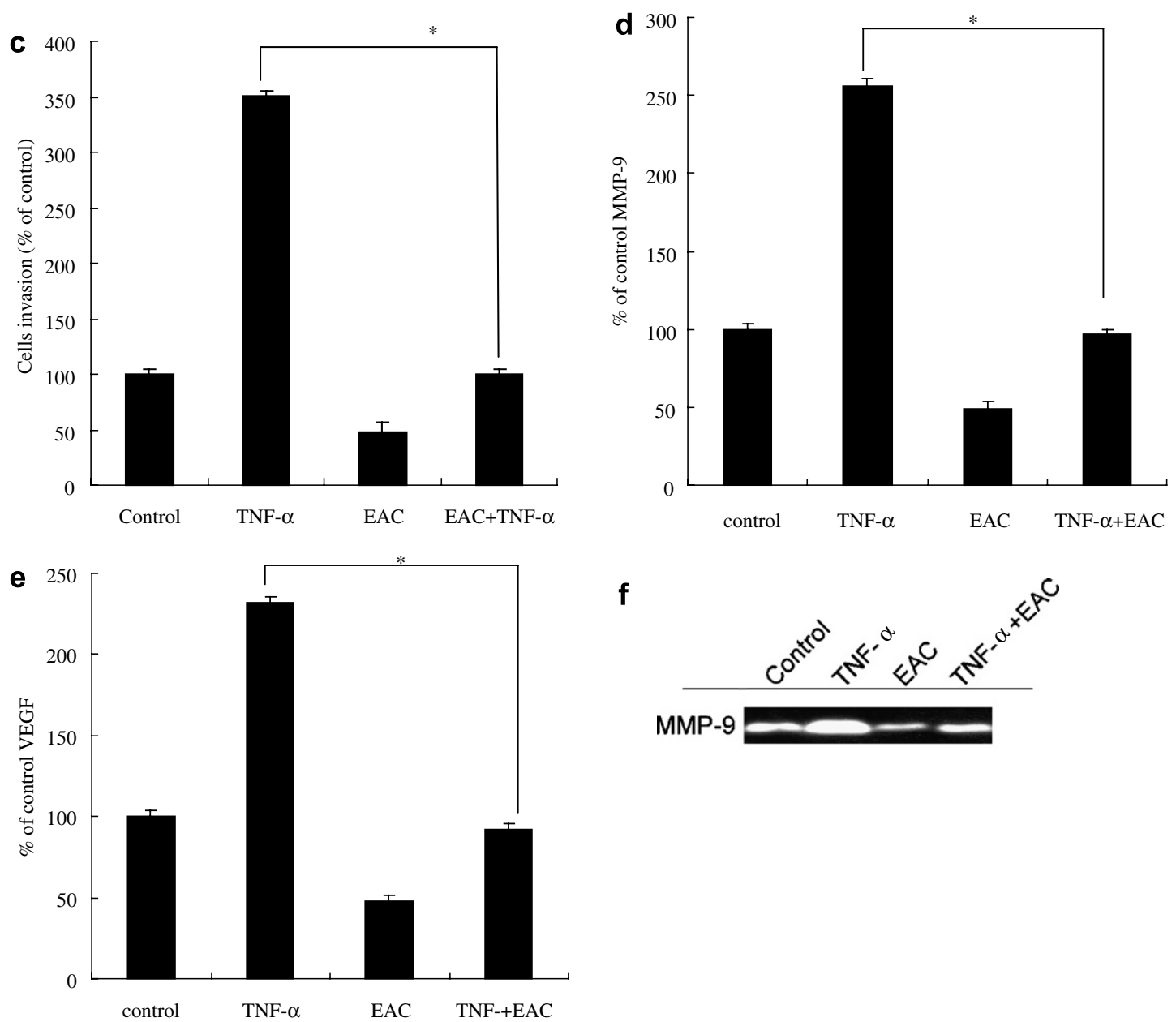

f

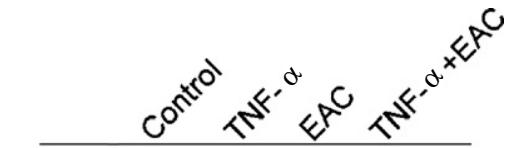

MMP-9

Free probe

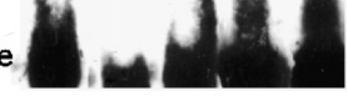




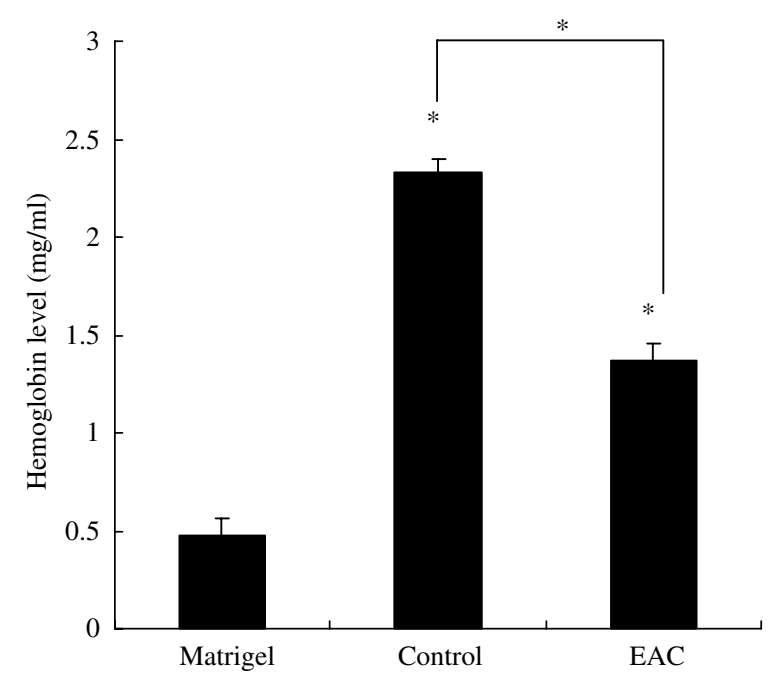

Fig. 5. Inhibition of EAC on angiogenesis in nude mice model. Nude mice were injected subcutaneously with Matrigel plugs, each plug containing $\mathrm{PLC} / \mathrm{PRF} / 5$ cells $(100 \mu \mathrm{l})$ with Matrigel $(200 \mu \mathrm{l})$ in the absence or presence of EAC $(30 \mu \mathrm{g} / \mathrm{ml})$. Each treatment group contained eight mice. The mice were euthanized 15 days after implantation. The degree of angiogenesis was determined by the levels of red blood cell (RBC) hemoglobin in the Matrigel plugs. The level of hemoglobin levels were determined by the Drabkin method. Each value is the means $\pm \mathrm{SD}$ of three independent determinations. The asterisk indicates a significant difference between two test groups, $\stackrel{*}{p}<0.05$.

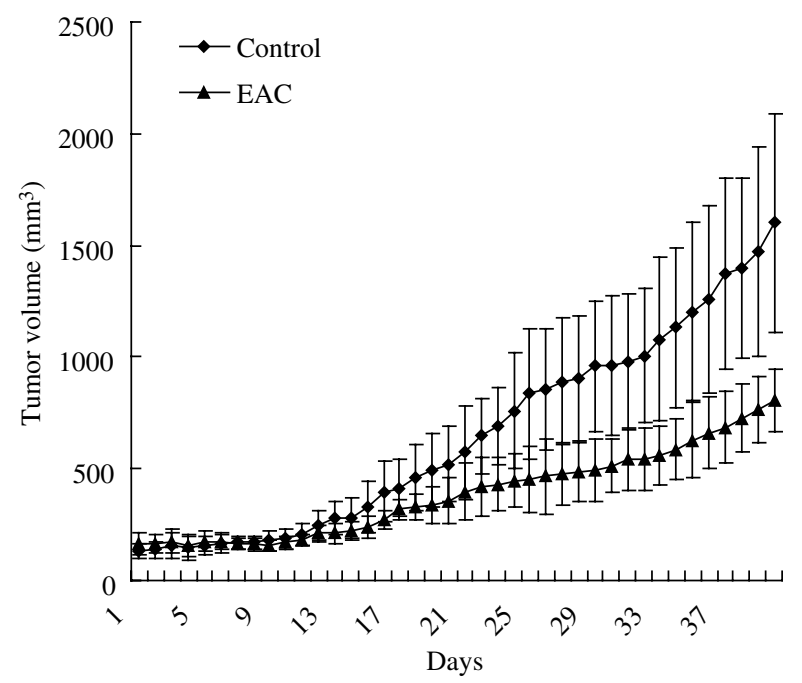

Fig. 6. Inhibition of tumor growth by EAC in nude mice model. The values were the mean of tumor volume measured at the indicated number of days post implant. Animals bearing pre-established tumors $(n=15$ per group) were dosed daily for 60 days with p.o. administration of EAC ( $300 \mathrm{mg} / \mathrm{kg}$ of body weight) or vehicle. During the 40 -day treatment, tumor volumes were estimated using measurements taken by means of external calipers $\left(\mathrm{mm}^{3}\right)$.

gen (Christofori, 2006; Hofmann et al., 2005). Among the more than 20 MMPs that have been identified, MMP-2 and MMP-9 have been postulated to play a critical role in tumor invasion and angiogenesis, and is indeed overexpressed in various human tumors (Deryugina and Quigley,
2006). This overexpression of MMP-9 and MMP2 confers a metastatic phenotype, and suppression of MMP-2 and MMP-9 impairs the cell migration of various tumors (Deryugina and Quigley, 2006; Hofmann et al., 2005; Rao et al., 2005). MMPs are under the control of specific tissue inhibitors of metalloproteinases (TIMPs). TIMPs play an important role in regulating the activity of the secreted metalloproteinases (Hofmann et al., 2005; Ikenaka et al., 2003). In addition to their ability to bind at the active site, TIMP-1 and TIMP-2 can form complexes with specific metalloproteinases (Ikenaka et al., 2003). In our studies, we have observed that EAC treatments not only decreased the expressions of MMP-2, MMP-9, and MT-1-MMP, but also inhibited the activity of MMP-2 and MMP-9. In addition, EAC treatment also increased the levels of MMP inhibitors, TIMP-1 and TIMP-2. This effect is correlated with the inhibition of EAC on PLC/PRF/5 cell invasion. These results suggest that EAC, a natural product capable of blocking both MMP-2/-9 protein expression and enzyme activity as shown in this study, is potentially an effective chemopreventive agent against cancer and tumor invasion.

Another important molecule involved in tumor cell invasion and metastasis is VEGF (Huang et al., 2005; Ross et al., 2001; Vosseler, 2005). VEGF is known to be specific for vascular endothelial cells (Huang et al., 2005). Investigations by Zhang et al. have shown that VEGF promotes migration and invasion of cancer cells (Zhang et al., 2006). Upregulation of VEGF expression has been demonstrated to be strongly associated with tumor growth, angiogenesis, and increased resistance of human liver cancer (Huang et al., 2005a,b; Turlin et al., 2002). Our results showed that EAC inhibits VEGF expression in vitro, which suggests that EAC may inhibit PLC/PRF/5 cancer angiogenesis resulting in the inhibition of cancer growth in vivo.

$\mathrm{NF}-\kappa \mathrm{B}$ activation has also been reported to be associated with cancer invasion and regulation of the expression of a variety of key proteins which are involved in various cellular responses, including invasion-related genes such as VEGF and MMP-9 (Shishodia et al., 2005). Many studies have revealed that blocking NF- $\kappa \mathrm{B}$ activity suppresses tumor growth and invasion of human cancer cells, including liver cancer cells, resulting in the inhibition of angiogenesis and cell invasion (Chung et al., 2004; Huang et al., 2005; Park et al., 2005). EAC inhibited NF-кB activation and expression of NF-кB-regulated gene production, such as MMP-9 and VEGF in liver carcinoma cells. In addition, TNF- $\alpha$ treatment increased the activation of $\mathrm{NF}-\kappa \mathrm{B}$, which was inhibited by EAC treatment. EAC also inhibited TNF- $\alpha$-induced cancer invasion and MMP-9 and VEFG upregulation. Therefore, it is possible that the suppression of PLC/PRF/5 cell invasion by EAC may be partly due to the inhibition of MMP-9 and VEGF expression mediated through by NF- $\mathrm{BB}$ inhibition.

In conclusion, we have provided evidence demonstrating that EAC inhibits invasion and both MMPs and VEGF protein expression and enzyme activity. EAC suppresses invasion of $\mathrm{PLC} / \mathrm{PRF} / 5$ cells by inhibition of 
$\mathrm{NF}-\kappa \mathrm{B}$ activity and sequentially reducing the expression and activity of MMP-9 in the cells. Therefore, we suggest that EAC could be potentially explored as a useful antiinvasive agent in the treatment of human liver carcinoma.

\section{Acknowledgement}

This study was supported by a research grant from the National Science Council of Taiwan (NSC94-2321-B-037001).

\section{References}

Aggarwal, B.B., 2004. Nuclear factor-kappa B: the enemy within. Cancer Cell 6, 203-208.

Chang, T.T., Chou, W.N., 2004. Antrodia cinnamomea reconsidered and A. salmomed sp. Nov. on Cunninghamia konishii in Taiwan. Bot. Bull. Acad. Sin. 45, 347-352.

Chirco, R., Liu, X.W., Jung, K.K., Kim, H.R., 2006. Novel functions of TIMPs in cell signaling. Cancer Metast. Rev. 25, 99-113.

Christofori, G., 2006. New signals from the invasive front. Nature 441, 444-450.

Chung, T.W., Moon, S.K., Chang, Y.C., Ko, J.H., Lee, Y.C., Cho, G., Kim, S.H., Kim, J.G., Kim, C.H., 2004. Novel and therapeutic effect of caffeic acid and caffeic acid phenyl ester on hepatocarcinoma cells: complete regression of hepatoma growth and metastasis by dual mechanism. FASEB J. 18, 1670-1681.

Denoyelle, C., Vasse, M., Korner, M., Mishal, Z., Ganne, F., Vannier, J.P., Soria, J., Soria, C., 2001. Cerivastatin, an inhibitor of HMG-CoA reductase, inhibits the signaling pathways involved in the invasiveness and metastatic properties of highly invasive breast cancer cell lines: an in vitro study. Carcinogenesis 22, 1139-1148.

Deryugina, E.I., Quigley, J.P., 2006. Matrix metalloproteinases and tumor metastasis. Cancer Metast. Rev. 25, 9-34.

Dixit, V., Mak, T.W., 2002. NF-kappaB signaling. Many roads lead to Madrid. Cell 111, 615-619.

Herr, I., Debatin, K.M., 2001. Cellular stress response and apoptosis in cancer therapy. Blood 98, 2603-2614.

Hofmann, U.B., Houben, R., Brocker, E.B., Becker, J.C., 2005. Role of matrix metalloproteinases in melanoma cell invasion. Biochimie 87, 307-314.

Hou, L., Li, Y., Jia, Y.H., Wang, B., Xin, Y., Ling, M.Y., Lu, S., 2001. Molecular mechanism about lymphogenous metastasis of hepatocarcinoma cells in mice. World J. Gastroenterol. 7, 532-536.

Hsiao, G., Shen, M.L., Lin, K.H., Lan, M.H., Wu, L.Y., Chou, D.S., Lin, C.H., Su, C.H., Sheu, J.R., 2003. Antioxidative and hepatoprotective effects of Antrodia camphorata extract. J. Agric. Food Chem. 51, 33023308.

Hsu, Y.L., Kuo, P.L., Lin, L.T., Lin, C.C., 2005a. Asiatic acid, a triterpene, induces apoptosis and cell cycle arrest through activation of extracellular signal-regulated kinase and p 38 mitogen-activated protein kinase pathways in human breast cancer cells. J. Pharmacol. Exp. Ther. 313, 333-344.

Hsu, Y.L., Kuo, Y.C., Kuo, P.L., Ng, L.T., Kuo, Y.H., Lin, C.C., 2005 b. Apoptotic effects of extract from Antrodia camphorata fruiting bodies in human hepatocellular carcinoma cell lines. Cancer Lett. 221, 77-89.

Hsu, Y.L., Cho, C.Y., Kuo, P.L., Huang, Y.T., Lin, C.C., 2006. Plumbagin (5-hydroxy-2-methyl-1,4-naphthoquinone) induces apoptosis and cell cycle arrest in A549 cells through p53 accumulation via cJun NH2-terminal kinase-mediated phosphorylation at serine 15 in vitro and in vivo. J. Pharmacol. Exp. Ther. 318, 484- 494.

Huang, S.M., Li, J., Harari, P.M., 2002. Molecular inhibition of angiogenesis and metastatic potential in human squamous cell carcinomas after epidermal growth factor receptor blockade. Mol. Cancer Ther. 1, 507-514.
Huang, G.W., Yang, L.Y., Lu, W.Q., 2005a. Expression of hypoxiainducible factor 1alpha and vascular endothelial growth factor in hepatocellular carcinoma: Impact on neovascularization and survival. World J. Gastroenterol. 11, 1705-1708.

Huang, S.C., Ho, C.T., Lin-Shiau, S.Y., Lin, J.K., 2005b. Carnosol inhibits the invasion of B16/F10 mouse melanoma cells by suppressing metalloproteinase-9 through down-regulating nuclear factor-kappa B and c-Jun. Biochem. Pharmacol. 69, 221-232.

Ikenaka, Y., Yoshiji, H., Kuriyama, S., Yoshii, J., Noguchi, R., Tsujinoue, H., Yanase, K., Namisaki, T., Imazu, H., Masaki, T., Fukui, H., 2003. Tissue inhibitor of metalloproteinases-1 (TIMP-1) inhibits tumor growth and angiogenesis in the TIMP-1 transgenic mouse model. Int. J. Cancer 105, 340-346.

Karin, M., Cao, M.Y., Greten, F.R., Li, Z.W., 2002. NF-kappaB in cancer: from innocent bystander to major culprit. Nat. Rev. Cancer 2, 301-310.

Ko, C.H., Shen, S.C., Lee, T.J., Chen, Y.C., 2005. Myricetin inhibits matrix metalloproteinase 2 protein expression and enzyme activity in colorectal carcinoma cells. Mol. Cancer Ther. 4, 281-290.

Kuo, P.L., Hsu, Y.L., Cho, C.Y., Ng, L.T., Kuo, Y.H., Lin, C.C., 2006. Apoptotic effects of Antrodia cinnamomea fruiting bodies extract are mediated through calcium and calpain-dependent pathways in Hep 3B cells. Food Chem. Toxicol. 44, 1316-1326.

Lee, I.H., Huang, R.L., Chen, C.T., Chen, H.C., Hsu, W.C., Lu, M.K., 2002. Antrodia camphorata polysaccharides exhibit anti-hepatitis B virus effects. FEMS Microbiol. Lett. 209, 63-67.

Liu, J.J., Huang, T.S., Hsu, M.L., Chen, C.C., Lin, W.S., Lu, F.J., Chang, W.H., 2004. Antitumor effects of the partially purified polysaccharides from Antrodia camphorata and the mechanism of its action. Toxicol. Appl. Pharmacol. 201, 186-193.

Liu, L.Z., Fang, J., Zhou, Q., Hu, X., Shi, X., Jiang, B.H., 2005. Apigenin inhibits expression of vascular endothelial growth factor and angiogenesis in human lung cancer cells: implication of chemoprevention of lung cancer. Mol. Pharmacol., 635-643.

Marrero, J.A., 2006. Hepatocellular carcinoma. Curr. Opin. Gastroenterol. 22, 248-253.

Motola-Kuba, D., Zamora-Valdes, D., Uribe, M., Mendez-Sanchez, N., 2006. Hepatocellular carcinoma. An overview. Ann. Hepatol. 5, 16-24.

Munshi, A., Kurland, J.F., Nishikawa, T., Chiao, P.J., Andreeff, M., Meyn, R.E., 2004. Inhibition of constitutively activated nuclear factorkappaB radio sensitizes human melanoma cells. Mol. Cancer Ther. 3, 985-992.

Nakamura, N., Hirakawa, A., Gao, J.J., Kakuda, H., Shiro, M., Komatsu, Y., Sheu, C.C., Hattori, M., 2004. Five new maleic and succinic acid derivatives from the mycelium of Antrodia camphorata and their cytotoxic effects on LLC tumor cell line. J. Nat. Prod. 67, 46-48.

Pan, S.L., Guh, J.H., Peng, C.Y., Wang, S.W., Chang, Y.L., Cheng, F.C., Chang, J.H., Kuo, S.C., Lee, F.Y., Teng, C.M., 2005. YC-1 [3-(5'hydroxymethyl-2'-furyl)-1-benzyl indazole] inhibits endothelial cell functions induced by angiogenic factors in vitro and angiogenesis in vivo models. J. Pharmacol. Exp. Ther. 314, 35-42.

Park, H.J., Chung, H.J., Min, H.Y., Park, E.J., Hong, J.Y., Kim, W.B., Kim, S.H., Lee, S.K., 2005. Inhibitory effect of DA-125, a new anthracyclin analog antitumor agent, on the invasion of human fibrosarcoma cells by down-regulating the matrix metalloproteinases. Biochem. Pharmacol. 71, 21-31.

Qin, L.X., Tang, Z.Y., 2004. Recent progress in predictive biomarkers for metastatic recurrence of human hepatocellular carcinoma: a review of the literature. J. Cancer Res. Clin. Oncol. 130, 497-513.

Rao, J.S., Gondi, C., Chetty, C., Chittivelu, S., Joseph, P.A., Lakka, S.S., 2005. Inhibition of invasion, angiogenesis, tumor growth, and metastasis by adenovirus-mediated transfer of antisense UPAR and MMP-9 in non-small cell lung cancer cells. Mol. Cancer Ther. 4, 1399-1408.

Ross, P.J., George, M., Cunningham, D., DiStefano, F., Andreyev, H.J., Workman, P., Clarke, P.A., 2001. Inhibition of Kirsten-ras expression in human colorectal cancer using rationally selected Kirsten-ras antisense oligonucleotides. Mol. Cancer Ther. 1, 29-41. 
Shen, Y.C., Wang, Y.H., Chou, Y.C., Chen, C.F., Lin, L.C., Chang, T.T., Tien, J.H., Chou, C.J., 2004. Evaluation of the Anti-Inflammatory Activity of Zhankuic Acids Isolated from the Fruiting Bodies of Antrodia camphorata. Planta Med. 70, 310-314.

Shishodia, S., Gutierrez, A.M., Lotan, R., Aggarwal, B.B., 2005. N-(4hydroxyphenyl)retinamide inhibits invasion, suppresses osteoclastogenesis, and potentiates apoptosis through down-regulation of I(kappa)B(alpha) kinase and nuclear factor-kappaB-regulated gene products. Cancer Res. 65, 9555-9565.

Song, T.Y., Yen, G.C., 2002. Antioxidant properties of Antrodia camphorata in submerged culture. J. Agric. Food Chem. 50, 33223327.

Srivastava, S.K., Singh, S.V., 2004. Cell cycle arrest, apoptosis induction and inhibition of nuclear factor kappa B activation in anti-proliferative activity of benzyl isothiocyanate against human pancreatic cancer cells. Carcinogenesis 25, 1701-1709.

Turlin, B., Le Quilleuc, D., Leroyer, P., Brissot, P., Deugnier, Y., Loreal, O., 2002. High vascular endothelial growth factor (VEGF) expression in chemically-induced hepatic microcancers in mice. J. Hepatol. 37, $620-624$.
Vosseler, S., Mirancea, N., Bohlen, P., Mueller, M.M., Fusenig, N.E., 2005. Angiogenesis inhibition by vascular endothelial growth factor receptor-2 blockade reduces stromal matrix metalloproteinase expression, normalizes stromal tissue, and reverts epithelial tumor phenotype in surface heterotransplants. Cancer Res. 65, 1294-1305.

Wang, G.J., Tseng, H.W., Chou, C.J., Tsai, T.H., Chen, C.T., Lu, M.K., 2003. The vasorelaxation of Antrodia camphorata mycelia: involvement of endothelial $\mathrm{Ca}\left({ }^{2+}\right)-\mathrm{NO}-\mathrm{cGMP}$ pathway. Life Sci. 73, 2769-2783.

Woodworth, C.D., Michael, E., Marker, D., Allen, S., Smith, L., Nees, M., 2005. Inhibition of the epidermal growth factor receptor increases expression of genes that stimulate inflammation, apoptosis, and cell attachment. Mol. Cancer Ther. 4, 650-658.

Zhang, A., Meng, L., Wang, Q., Xi, L., Chen, G., Wang, S., Zhou, J., Lu, Y., Ma, D., 2006. Enhanced in vitro invasiveness of ovarian cancer cells through up-regulation of VEGF and induction of MMP-2. Oncol. Rep. 15, 831-836.

Zucker, S., Cao, J., Chen, W.T., 2000. Critical appraisal of the use of matrix metalloproteinase inhibitors in cancer treatment. Oncogene 19, $6642-6650$. 